\title{
STUDI TENTANG KEJADIAN BENDUNGAN ASI PADA IBU NIFAS DI PUSKESMAS JUMPANDANG BARU MAKASSAR
}

\section{The Study Of The Incidence Of Breast Engorgement Postpartum Mothers At Puskesmas Jumpandang Baru Makassar}

\author{
${ }^{1)}$ Maria Sonda, ${ }^{2}$ Andi Syintha Ida, ${ }^{3)}$ Hastuti Husain \\ 1] Jurusan Kebidanan Poltekkes Kemenkes Makassar Sebagai Penulis 1 \\ email: maria_sonda@poltekkesmks.ac.id \\ 2]Jurusan Kebidanan Poltekkes Kemenkes Makassar Sebagai Penulis 2 \\ email: synta_ida@poltekkes-mks.ac.id \\ 3]Jurusan Kebidanan Poltekkes Kemenkes Makassar Sebagai Penulis 3 \\ email: hastutihusain16@gmail.com
}

\begin{abstract}
ABSTRAK
Pada permulaan nifas apabila bayi tidak menyusu dengan baik, atau kemudian apabila kelenjar-kelenjar tidak dikosongkan dengan sempurna, terjadi pembendungan air susu.

Tujuan umum dalam penelitian ini adalah Untuk mengetahui Penyebab Kejadian Bendungan ASI pada ibu nifas di Puskesmas Jumpandang Baru Makassar.

Penelitian ini menggunakan metode penelitian Kuantitatif dengan desain penelitian deskripsi analitik dan rancangan penelitian Cross Sectional. Penelitian ini dilaksanakan pada tahun 2019 di Puskesmas Jumpandang Baru Makassar. Populasi dalam penelitian ini adalah ibu nifas normal yang dirawat di Puskesmas Jumpandang baru dengan jumlah sampel sebanyak 30 orang. Pengambilan sampel dilakukan dengan metode Non Probability sampling yaitu Purposive Random Sampling yang memenuhi Kriteria inklusi dan eksklusi. Proses pengumpulan data dalam penelitian ini menggunakan lembar observasi. Data yang didapat dianalisa menggunakan analisa univariat dan bivariat dengan uji chi aquare.

Hasil penelitian menunjukkan bahwa paritas, posisi menyusui, keadaan puting susu dan frekwensi menyusui dapat menyebabkan bendungan ASI dengan hasil uji Chi square $<0.005$, yakni $p$ value paritas 0,000 , posisi menyusui 0,000 , keadaan puting susu 0,37 dan frekwensi menyusui 0,000 .

Diharapkan dukungan penuh dari bidan dan keluarga agar dapat membantu ibu nifas selama proses menyusui sehingga pemberian ASI dapat maksimal.
\end{abstract}

Kata Kunci : Bendungan ASI, Ibu Nifas

\section{ABSTRACT}

At the beginning of the puerperium if the baby does not suckle properly, or later if the glands are not emptied completely, there is a blockage of milk.

The general objective in this study was to determine the cause of breast milk dams in post partum mothers at the Jumpandang Baru Public Health Center in Makassar.

This study uses a quantitative research method with analytic description research design and cross sectional research design. This research was carried out in 2019 at Puskesmas Jumpandang Baru Makassar. The population in this study was normal postpartum mothers who were treated at the new Jumpandang Health Center with a total sample of 30 people. Sampling is done by the Non Probability sampling method that is Purposive Random Sampling that meets the inclusion and exclusion criteria. The process of collecting data in this study uses observation sheets. The data obtained were analyzed using univariate and bivariate analysis with the chi square test.

The results showed that parity, breastfeeding position, nipple state and frequency of breastfeeding can cause breast engorgement with Chi square test results $<0.005$, ie $p$ value parity 0,000 , breastfeeding position 0,000 , nipple state 0.37 and frequency of breastfeeding 0,000 .

Full support from midwives and families is expected to be able to help postpartum mothers during breastfeeding so that breastfeeding can be maximized.

Keywords: Breast Engorgement, Mother Postpartum.

\section{PENDAHULUAN}

Pada permulaan nifas apabila bayi tidak menyusu dengan baik, atau kemudian apabila kelenjar-kelenjar tidak dikosongkan dengan sempurna, terjadi pembendungan air susu. Tanda tanda pembendungan Air Susu yaitu pada perabaan payudara panas dan keras, nyeri, namun suhu badan tak naik. Puting susu datar juga dapat menyulitkan bayi untuk menyusu. Terkadang pengeluaran air susu juga terhalang penyempitan duktus laktiferi dikarenakan pembesaran vena dan pembuluh limfe (Sarwono, 2008). 
Menurut Herdini Widyaning pertiwi, 2018 kejadian Bendungan ASI yang disebabkan oleh pengeluaran air susu yang tidak lancar, karena bayi tidak cukup sering menyusu pada ibu nya. Gangguan ini dapat menjadi lebih parah apabila ibu jarang menyusukan bayinya, akibatnya bayi tidak mendapatkan ASI secara Eksklusif dan apabila tidak segera di tangani maka akan menyebabkan Bendungan ASI pada Payudara.

Menurut Data Survey Demografi dan Kesehatan Indonesia tahun 2015 menyebutkan bahwa terdapat ibu nifas yang mengalami Bendungan ASI sebanyak 35.985 atau $(15,60 \%)$ ibu nifas, serta pada tahun 2015 ibu nifas yang mengalami Bendungan ASI sebanyak 77.231 atau (37, $12 \%)$ ibu nifas ( SDKI, 2015).

Berdasarkan data awal yang dilakukan di Puskesmas Jumpandang Baru pada tahun 2018, jumlah ibu nifas yang mengalami bendungan ASI sebanyak $19,56 \%$. Pengamatan yang dilakukan oleh peneliti di Puskesmas Jumpandang Baru, hampir tiap hari menemukan kasus bendungan ASI pada ibu nifas.

Berdasarkan data diatas, maka penulis tertarik meneliti kasus tentang kejadian bendungan ASI di Puskesmas Jumpandang Baru Kota Makassar.

\section{BAHAN DAN METODE}

\section{Lokasi, Populasi dan Sampel Penelitian}

Penelitian ini menggunakan metode penelitian Kuantitatif dengan desain penelitian deskripsi analitik dan rancangan penelitian Cross Sectional. Tahapan dalam penelitian ini adalah: mengamati ibu nifas untuk mengumpulkan variabel independet dan variabel dependet secara bersamaan.

Penelitian ini dilaksanakan di Puskesmas Jumpandang Baru Makassar.

Populasi dalam penelitian ini adalah semua ibu nifas di Puskesmas Jumpandang Baru selama tahun 2018

Sampel penelitian ini sebanyak 30 orang ibu nifas. Pengambilan sampel dilakukan dengan metode non probability sampling yaitu Purposive sampling yang memenuhi kriteria inklusi dan eksklusi.

\section{HASIL PENELITIAN}

1. Analisis Univariat

Tabel 1. Distribusi lbu Nifas berdasarkan Paritas di Puskesmas Jumpandang Baru

\begin{tabular}{ccc}
\hline $\begin{array}{c}\text { Paritas lbu } \\
\text { Nifas }\end{array}$ & $\mathbf{N}=\mathbf{3 0}$ & $\begin{array}{c}\text { Persentase } \\
(\%)\end{array}$ \\
\hline Primipara & 12 & $40 \%$ \\
Multipara & 18 & $60 \%$ \\
\hline Sumber data primer tahun 2017
\end{tabular}

Sumber data primer tahun 2017
Pada tabel diatas, menunjukkan distribusi ibu nifas berdasarkan Paritas yakni dari $30 \mathrm{lbu}$ nifas, sebanyak $12(40 \%)$ dengan primipara, dan ibu nifas dengan multipara sebanyak 18 $(60 \%)$ orang.

Tabel 2. Distribusi Ibu Nifas Berdasarkan Posisi Menyusui di Puskesmas Jumpandang Baru

\begin{tabular}{lcc}
\hline $\begin{array}{l}\text { Posisi } \\
\text { menyusui }\end{array}$ & $\mathbf{N}=\mathbf{3 0}$ & Persentase (\%) \\
\hline Benar & 17 & $56,67 \%$ \\
Tidak & 13 & $43,33 \%$ \\
Benar & & \\
Sumber data primer tahun 2019 &
\end{tabular}

Pada tabel diatas, menunjukkan distribusi ibu nifas berdasarkan Posisi menyusui. Ibu nifas dengan posisi menyusui yang benar, sebanyak 17 (56,67\%) orang sedang ibu nifas dengan posisi menyusui tidak benar sebanyak $13(43,33 \%)$ orang.

Tabel 3. Distribusi lbu Nifas Berdasarkan Keadaan Puting Susu di Puskesmas Jumpandang Baru

\begin{tabular}{ccc}
\hline $\begin{array}{c}\text { Keadaan } \\
\text { puting susu }\end{array}$ & $\mathbf{N}=\mathbf{3 0}$ & Persentase (\%) \\
\hline Bagus & 23 & $76,67 \%$ \\
Kurang & 7 & $23,33 \%$ \\
Bagus & \multicolumn{2}{l}{} \\
\hline \multicolumn{3}{l}{ Sumber data primer tahun 2019}
\end{tabular}

Pada tabel diatas, menunjukkan distribusi ibu nifas berdasarkan keadaan puting susu. Ibu nifas dengan keadaan puting susu yang bagus, sebanyak $23(76,67 \%)$ orang sedang ibu nifas dengan keadaan puting susu kurang bagus sebanyak $7(23,33 \%)$ orang.

Tabel 4. Distribusi lbu Nifas Berdasarkan Frekwensi menyusui di Puskesmas Jumpandang Baru

\begin{tabular}{lcc}
\hline $\begin{array}{l}\text { Frekwensi } \\
\text { menyusui }\end{array}$ & $\mathbf{N}=\mathbf{3 0}$ & $\begin{array}{c}\text { Persentase } \\
\mathbf{( \% )}\end{array}$ \\
\hline Bagus & 19 & $63,33 \%$ \\
Kurang & 11 & $36,67 \%$ \\
Bagus & \multicolumn{2}{l}{} \\
\hline \multicolumn{2}{l}{ Sumber data primer tahun 2019 }
\end{tabular}

Pada tabel diatas, menunjukkan distribusi ibu nifas berdasarkan Frekwensi Menyusui. Ibu nifas dengan frekwensi menyusui yang bagus, sebanyak $19(63,33 \%)$ orang sedang ibu nifas dengan frekwensi menyusu kurang bagus sebanyak 11 $(36,67 \%)$ orang.

Tabel 5. Distribusi Ibu Nifas menurut Kejadian Bendungan ASI di Puskesmas Jumpandang Baru 
e-issn : 2622-0148, p-issn : 2087-0035

\begin{tabular}{ccc}
\hline \hline $\begin{array}{c}\text { Kejadian } \\
\text { Bendungan ASI }\end{array}$ & $\mathbf{N}=\mathbf{3 0}$ & $\begin{array}{c}\text { Persentase } \\
\text { (\%) }\end{array}$ \\
\hline Ya & 8 & $26,67 \%$ \\
Tidak & 22 & $73,33 \%$ \\
\hline
\end{tabular}

Sumber data primer tahun 2019

Pada tabel diatas, menunjukkan distribusi ibu nifas berdasarkan Kejadian Bendungan ASI. Ibu nifas yang mengalami bendungan ASI, sebanyak 8 $(26,67 \%)$ orang sedang ibu nifas yang tidak mengalami bendungan ASI sebanyak 22 (73,33\%) orang.

\section{Analisis Bivariat}

Tabel 6. Kejadian Bendungan ASI Berdasarkan Paritas di Puskesmas Jumpandang Baru

\begin{tabular}{|c|c|c|c|c|}
\hline \multirow[t]{2}{*}{ Paritas } & \multicolumn{2}{|c|}{$\begin{array}{c}\text { Kejadian } \\
\text { Bendungan ASI }\end{array}$} & \multirow[t]{2}{*}{ Total } & \multirow[t]{2}{*}{$\begin{array}{c}P \\
\text { Value }\end{array}$} \\
\hline & $\mathrm{Ya}$ & Tidak & & \\
\hline Primipara & $\begin{array}{c}8 \\
(66,7)\end{array}$ & $\begin{array}{c}4 \\
(33,3)\end{array}$ & 12 & \\
\hline Multipara & $\begin{array}{c}0 \\
(0)\end{array}$ & $\begin{array}{c}18 \\
(100)\end{array}$ & 18 & 0.000 \\
\hline Jumlah & $\begin{array}{c}8 \\
(26,7)\end{array}$ & $\begin{array}{c}22 \\
(73,3)\end{array}$ & 30 & \\
\hline
\end{tabular}

Sumber data primer tahun 2019

Tabel di atas menunjukkan kejadian bendungan ASI berdasarkan paritas dimana dari 12 orang ibu nifas primipara, terdapat 8 orang $(66,7 \%)$ yang mengalami bendungan ASI dan yang tidak mengalami bendungan ASI sebanyak 4 orang $(33,33 \%)$ sedang dari 18 orang multipara, tidak ada ibu yang mengalami bendungan ASI.

Hasi uji statistik dengan menggunakan uji chi square didapatkan nilai $p$ value $=0,000<0,05$ maka dapat disimpulkan bahwa ada pengaruh paritas terhadap kejadian bendungan ASI pada ibu nifas.

Tabel 7. Kejadian Bendungan ASI Berdasarkan Posisi Menyusui di Puskesmas Jumpandang Baru

\begin{tabular}{|c|c|c|c|c|}
\hline \multirow{2}{*}{$\begin{array}{l}\text { Posisi } \\
\text { menyusui }\end{array}$} & \multicolumn{2}{|c|}{$\begin{array}{c}\text { Kejadian } \\
\text { Bendungan ASI }\end{array}$} & \multirow[t]{2}{*}{$\begin{array}{c}\text { Tota } \\
\text { I }\end{array}$} & \multirow[t]{2}{*}{$\begin{array}{c}P \\
\text { Value }\end{array}$} \\
\hline & $\mathrm{Ya}$ & Tidak & & \\
\hline Benar & $\begin{array}{c}0 \\
(0)\end{array}$ & $\begin{array}{c}17 \\
(100)\end{array}$ & 17 & \\
\hline Salah & $\begin{array}{c}8 \\
(61,5)\end{array}$ & $\begin{array}{c}5 \\
(38,5)\end{array}$ & 13 & 0.000 \\
\hline Jumlah & $\begin{array}{c}8 \\
(26,7)\end{array}$ & $\begin{array}{c}22 \\
(73,3)\end{array}$ & 30 & \\
\hline
\end{tabular}

Sumber data primer tahun 2019

Tabel di atas menunjukkan kejadian bendungan ASI berdasarkan posisi menyusui dimana dari 17 orang ibu nifas dengan posisi menyusui yang benar, tidak ada yang mengalami bendungan ASI sedang dari 13 orang dengan posisi menyusui yang salah, terdapat $8(61,5 \%)$ ibu nifas yang mengalami bendungan ASI dan $5(38,5 \%)$ ibu nifas yang tidak mengalami bendungan ASI.

Hasi uji statistik dengan menggunakan uji chi square didapatkan nilai $p$ value $=0,000<0,05$ maka dapat disimpulkan bahwa ada pengaruh posisi menyusui terhadap kejadian bendungan ASI pada ibu nifas.

Tabel 8. Kejadian Bendungan ASI Berdasarkan Keadaan Puting Susu di Puskesmas Jumpandang Baru

\begin{tabular}{|c|c|c|c|c|}
\hline \multirow{2}{*}{$\begin{array}{c}\text { Keadaan } \\
\text { puting } \\
\text { susu }\end{array}$} & \multicolumn{2}{|c|}{$\begin{array}{c}\text { Kejadian } \\
\text { Bendungan ASI }\end{array}$} & \multirow[t]{2}{*}{ Total } & \multirow[t]{2}{*}{$\begin{array}{c}P \\
\text { Value }\end{array}$} \\
\hline & $\mathrm{Ya}$ & Tidak & & \\
\hline Bagus & $\begin{array}{c}4 \\
(17,4)\end{array}$ & $\begin{array}{c}19 \\
(82,6)\end{array}$ & 23 & \\
\hline $\begin{array}{l}\text { Kurang } \\
\text { Bagus }\end{array}$ & $\begin{array}{c}4 \\
(57,1)\end{array}$ & $\begin{array}{c}3 \\
(42,9)\end{array}$ & 7 & 0.000 \\
\hline Jumlah & $\begin{array}{c}8 \\
(26,7)\end{array}$ & $\begin{array}{c}22 \\
(73,3)\end{array}$ & 30 & \\
\hline
\end{tabular}

Sumber data primer tahun 2019

Tabel di atas menunjukkan kejadian bendungan ASI berdasarkan keadaan puting susu dimana dari 23 orang ibu nifas dengan puting susu bagus, terdapat $4(17,4 \%)$ ibu nifas yang mengalami bendungan ASI dan 19 (82,6\%) ibu nifas yang tidak mengalami bendungan $\mathrm{ASI}$ sedang dari 7 orang dengan puting susu kurang bagus, terdapat 4 $(57,1 \%)$ ibu nifas yang mengalami bendungan ASI dan $3(42,9 \%)$ ibu nifas yang tidak mengalami bendungan ASI.

Hasi uji statistik dengan menggunakan uji chi square didapatkan nilai $p$ value $=0,037<0,05$ maka dapat disimpulkan bahwa ada pengaruh keadaan puting susu terhadap kejadian bendungan ASI pada ibu nifas.

Tabel 9. Kejadian Bendungan ASI Berdasarkan Frekwensi Menyusui di Puskesmas Jumpandang Baru

\begin{tabular}{|c|c|c|c|c|}
\hline \multirow{2}{*}{$\begin{array}{c}\text { Frekwen } \\
\text { si } \\
\text { Menyus } \\
\text { u }\end{array}$} & \multicolumn{2}{|c|}{$\begin{array}{c}\text { Kejadian } \\
\text { Bendungan ASI }\end{array}$} & \multirow[t]{2}{*}{ Total } & \multirow[t]{2}{*}{$\begin{array}{c}P \\
\text { Value }\end{array}$} \\
\hline & $\mathrm{Ya}$ & Tidak & & \\
\hline$\leq 2$ jam & $\begin{array}{c}1 \\
(5,3)\end{array}$ & $\begin{array}{c}18 \\
(94,7)\end{array}$ & 19 & \\
\hline$>2 \mathrm{jam}$ & $\begin{array}{c}7 \\
(63,6) \\
\end{array}$ & $\begin{array}{c}4 \\
(36,4) \\
\end{array}$ & 11 & 0.000 \\
\hline Jumlah & $\begin{array}{c}8 \\
(26,7) \\
\end{array}$ & $\begin{array}{c}22 \\
(73,3) \\
\end{array}$ & 30 & \\
\hline
\end{tabular}

Sumber data primer tahun 2019

Tabel di atas menunjukkan kejadian bendungan ASI berdasarkan frekwensi menyusui 
dimana dari 19 orang ibu nifas dengan frekwensi menyusui tiap $\leq 2 \mathrm{jam}$, terdapat $1(5,3 \%)$ ibu nifas yang mengalami bendungan ASI dan $18(82,6 \%)$ ibu nifas yang tidak mengalami bendungan ASI sedang dari 11 orang dengan frekwensi menyusui tiap $>2$ jam, terdapat $7(63,6 \%)$ ibu nifas yang mengalami bendungan ASI dan $3(42,9 \%)$ ibu nifas yang tidak mengalami bendungan $\mathrm{ASI}$.

Hasi uji statistik dengan menggunakan uji chi square didapatkan nilai $p$ value $=0,000<0,05$ maka dapat disimpulkan bahwa ada pengaruh frekwensi menyusui terhadap kejadian bendungan ASI pada ibu nifas.

\section{PEMBAHASAN}

1. Kejadian bendungan ASI berdasarkan paritas Hasil penelitian ini menunjukkan bahwa dari 30 ibu nifas terdapat 8 orang yang mengalami bendungan ASI dan semua ibu yang mengalami bendungan ASI adalah ibu nifas yang primipara. Hal ini menunjukkan bahwa paritas sangat berpengaruh terhadap kejadian bendungan ASI. Hal ini diperkuat dengan hasil uji Chi Square dengan $p$ value $0,000<0,05$.

Ibu nifas primipara cenderung mengalami bendungan ASI diakibatkan oleh faktor pengetahuan dan pengalaman mereka yang baru pertama kali melahirkan. Kurangnya pengalaman bagi ibu primipara dalam menyusui bayi

Hasil penelitian ini sejalan dengan penelitian yang dilakukan oleh Asri Hayati, 2013 yang menyatakan bahwa mayoritas ibu nifas yang mengalami bendungan ASI adalah ibu primipara.

2. Kejadian bendungan ASI berdasarkan posisi menyusui

Hasil penelitian ini menunjukkan bahwa dari 30 ibu nifas terdapat 8 orang yang mengalami bendungan ASI dan semua ibu yang mengalami bendungan ASI adalah ibu nifas dengan posisi menyusui yang tidak benar. Hal ini menunjukkan bahwa posisi menyusui sangat berpengaruh terhadap kejadian bendungan ASI. Hal ini diperkuat dengan hasil uji Chi Square dengan $p$ value $0,000<0,05$.

Hasil penelitian ini sejalan dengan hasil penelitian yang dilakukan oleh lilis Nurul, $2015 \mathrm{di}$ BPM Ida Riyani Magelang yang mendapatkan hasil bahwa ibu nifas mengalami bendungan ASI karena tidak menyusui bayinya dengan teknik yang benar.

Menurut Tuti Meihartati, 2018 Posisi menyusui sangat berpengaruh terhadap kejadian bendungan ASI. Hal ini diakibatkan oleh posisi atau yang tidak tepat sehingga ASI tidak keluar secara maksimal dari payudara.

Teknik yang salah dalam menyusui dapat mengakibatkan puting susu menjadi lecet dan menimbulkan rasa nyeri pada saat bayi menyusu. Akibatnya lbu tidak mau menyusui bayinya dan terjadi bendungan ASI.

3. Kejadian bendungan ASI berdasarkan keadaan puting susu

Hasil penelitian ini menunjukkan bahwa dari 30 ibu nifas terdapat 8 orang yang mengalami bendungan ASI dimana dari 8 orang yang mengalami bendungan ASI terdapat 4 orang dengan keadaan puting susu bagus dan 4 orang dengan puting susu kurang bagus. Hal ini menunjukkan bahwa keadaan puting susu cukup berpengaruh terhadap kejadian bendungan ASI. Hal ini diperkuat dengan hasil uji Chi Square dengan $p$ value $0,037<0,05$.

Puting susu berperan penting dalam pengeluaran ASI. Puting susu yang tidak terbentuk sempurna dapat mengakibatkan ibu nifas tidak dapat menyusui bayinya dengan baik dan bayi juga tidak dapat menyusu dengan maksimal. Hal ini mengakibatkan pengosongan payudara menjadi terganggu (Manuaba:317)..

Puting susu yang terbenam akan menyulitkan bayi dalam menyusu. Karena bayi tidak dapat menghisap puting dan areola, bayi tidak mau menyusu dan akibatnya terjadi bendungan ASI, sedangkan puting susu yang panjang menimbulkan kesulitan pada saat bayi menyusu karena bayi tidak dapat menghisap areola dan merangsang sinus laktiferus untuk mengeluarkan ASI. Akibatnya ASI tertahan dan menimbulkan bendungan ASI) (Manuaba:317).

4. Kejadian bendungan ASI berdasarkan frekwensi menyusui

Hasil penelitian ini menunjukkan bahwa dari 30 ibu nifas terdapat 8 orang yang mengalami bendungan ASI. Dari 8 orang yang mengalami bendungan ASI terdapat 7 orang dengan frekwensi menyusui tiap $>2$ jam dan 1 orang dengan frekwensi menyusui tiap $\leq 2 \mathrm{jam}$. Hal ini menunjukkan bahwa frekwensi menyusui sangat berpengaruh terhadap kejadian bendungan ASI. Hal ini diperkuat dengan hasil uji Chi Square dengan $p$ value $0,000<0,05$.

Frekwensi menyusui sangat berperan dalam kejadian bendungan ASI. ASI yang tidak sering dikosongkan tiap 2 jam dapat mengakibatkan payudara penuh dan menimbulkan rasa nyeri pada ibu nifas. Dalam masa laktasi, terjadi peningkatan produksi ASI pada lbu yang produksi ASI-nya berlebihan. apabila bayi sudah kenyang dan selesai menyusu, \& payudara tidak dikosongkan, maka masih terdapat sisa ASI di dalam payudara. Sisa ASI tersebut jika tidak dikeluarkan dapat menimbulkan bendungan ASI (Tuti Meihartati, 2018). 


\section{KESIMPULAN DAN SARAN}

\section{A. Kesimpulan}

Paritas berperan penting dengan kejadian bendungan ASI dimana semua ibu nifas yang mengalami bendungan ASI adalah ibu nifas primipara.

Posisi menyusui dapat menyebabkan bendungan ASI dimana posisi ibu yang kurang tepat dalam menyusui lebih banyak mengalami bendungan ASI dibanding posisi menyusui yang benar.

Keadaan puting susu dapat menyebabkan bendungan ASI dimana ibu nifas dengan keadaan puting susu kurang bagus lebih banyak yang mengalami bendungan ASI dibanding yang ibu nifas dengan puting susu bagus.

Frekwensi menyusui dapat menyebabkan bendungan ASI dimana ibu nifas yang selang waktu menyusui > 2 jam lebih banyak mengalami bendungan ASI dibanding ibu yang menyusui dengan selang waktu $<2$ jam.
B. Saran

1. Diharapkan pemberian motivasi dan dukungan penuh dari petugas kesehatan kepada ibu nifas agar dapat menyusui bayinya dengan ASI saja sampai umur 6 bulan.

2. Ibu primipara mendapatkan pendidikan kesehatan tentang cara menyusui yang baik dan benar sehingga bendungan ASI tidak terjadi.

3. Perlunya identifikasi ibu dengan puting susu kurang bagus sejak kehamilan agar dapat diantisipasi sesegera mungkin bila sudah melahirkan agar pemberian ASI dapat maksimal

Perlunya pendidikan kesehatan tentang perawatan payudara pada ibu nifas agar dapat memperlancar pengeluaran ASI

\section{UCAPAN TERIMA KASIH}

Ucapan terima kasih kami ucapkan terutama kepada seluruh pihak yang membantu penulis untuk keberlangsungan penelitian ini

\section{DAFTAR PUSTAKA}

Arikunto, S. (2010). Prosedur Penelitian Suatu Pendekatan Praktek. Jakarta : Rineka Cipta.

Anggraini, Yetti. 2010. Asuhan Kebidanan Masa Nifas. Yogyakarta: Pustaka Rihanna

Cunningham, M.D. 2008.Obstetri William. Jakarta: EGC Departemen Kesehatan RI. 2009.

Manuaba. Gde. 1998. IImu Kebidanan, Penyakit Kandungan \& Keluarga Berencana untuk Pendidikan Bidan. Jakarta : ECG

Profil Kesehatan Indonesia tahun 2012. Jakarta:Departemen Kesehatan RI Dinas Kesehatan Jawa Tengah . 2012.

Prawirohardjo. 2010. IImu Kebidanan. Jakarta: PT Bina Pustaka Sarwono Prawirohardjo

Roesli. (2010). Panduan Praktis Menyusui. Pustaka Bunda : Jakarta

Ramaiah, 2007. ASI dan Menyusui. Jakarta: PT. Bhuana IImu Populer 